\title{
XXXV. On some compounds of chrome
}

\section{Grouvelle}

To cite this article: M. Grouvelle (1822) XXXV. On some compounds of chrome, Philosophical Magazine Series 1, 59:286, 127-130, DOI: $10.1080 / 14786442208652702$

To link to this article: http://dx.doi.org/10.1080/14786442208652702

曲 Published online: 27 Jul 2009.

Submit your article to this journal ๔

III Article views: 4

Q View related articles $\asymp$ 
nution of the number of deaths from small pox may fairly be attributed to the wider diffusion of vaccination.

(Signed)

Henry Halford, President. $\left.\begin{array}{l}\text { Algn. Frampton, } \\ \text { Tho. Hume, } \\ \text { Charles Badham, } \\ \text { Robert Lloyd, }\end{array}\right\} \begin{aligned} & \text { Censors of the } \\ & \text { Roval College } \\ & \text { of Physicians. }\end{aligned}$ Everard Home, Master of the Royal College of Surgeons.
Willam Blizard, $\{$ Governors of the Royal College of Henry Cline, $\}$ Surgeons.

By order of the Board,

James Henvey, M.D., Registrar.

XXXV. On some Compounds of Chrome. By M. GRouvelle* *

Acid Chromate of Polash.

Acro chromate of potash is anhydrous: I obtained it by digesting the neutral chromate of potash with nitric acid, separating from the first crop of crystals all those of nitre, and then redissolving and again crystallizing the chromate. When this salt is strongly calcined it melts, and passes to the state of neutral chromate, giving up half its acid, which is decomposed, and leaving an oxide of chrome crystallized in brilliant green scales. The neutral chromate thus obtained was analysed by a solution of sulphurous acid, which changed it instantaneously into sulphate of potash, sulphate and sulphite of chrome. The metallic oxide was precipitated by ammonia, and the sulphate of potash evaporated. The super-chromate, therefore, contains twice as much acid as the neutral chromate, and is composed of

Chromic acid (two atoms) ......68.846

Potash (one atom) .......... 31 154

$100 \cdot 000$

\section{Carlonate of Chrome.}

On pouring sulphurous acid and potash into liquid chromic acid, M.Vauquelin obtained a brown precipitate, which he thinks is an oxide more oxygenated than the green oxide of chrome. This, however, is not an oxide, but a carbonate of chrome. It dissolves without effervescence in diluted acids. When boiled in distilled water it is decomposed, and the green oxide and carbonic acid gas are obtained, on which account care should be taken not to wash it with hot water. This salt may also be procured in another way, that is, by passing a current of nitrous

* From the Annales de Chimie et de Physitipe. 
gas and air through chromate of potash mixed with an alkaline carbonate. Carbonate of chrome then falls down on boiling the mixture; but if it contains too much nitrous acid, the whole will pass to the state of nitrate of chrome. This method, however, often fails: it is evidently the nitrous acid which reduces the chromic, and the oxide thus produced attracts to itself the carbonic acid driven from the carbonate by an excess of acid. A better method of obtaining this carbonate is, to evaporate to dryness, a mixture of nitrate of ammonia, chromate, and carbonate of potash; or of muriate of ammonia, with a nitrate, carbonate, and chromate of alkali. This mixture, when gently dried, blackens; it is then to be re-dissolved in water, and a drop or two of amnonia, which has the effect, I beheve, of separating a small quantity of carbonate of chrome which the nitrate of ammonia had retained in solution.

If too high a degree of heat be applied, the excess of nitrate will re-produce the chromate. Here it is the protoxide of azote (nitrous oxide) in its nascent state which decomposes the chromic acid; for, when once become gaseous, it has no longer this property. If, on the other hand, the chromate of potash and the nitrate of aumonia are acidified with nitric acid, and dried and heated in a tube protected from the contuct of air, no carbonate of chrome whatever is obtained.

A mixture of nitre and muriate of ammonia acts in the same manner as nitrate of ammonia, because a donble decomposition takes place, on account of the facility with which the nitrate of ammonia assumes the gaseous form. This double deconposition always oscurs when these salts are heated with the nitrate of any inetal capable of forming a fxed chloruret with muriate of ammonia.

Therefore, to obtain nitrous oxide, instead of employing caustic nitrate of ammonia, we may use nitrate of potash aud muriate of ammonia, in the proportions suited to complete decomposition, leaving, however, an excess of nitrate to avoid any sublimation of the sal-ammoniac. 'The proportions may be about three parts of nitre to one of sal-ammoniac.

\section{Chromites.}

The existence of these salts is still doubtful, and Berzelius has not yet ventured to adinit them positively in his System of $\mathrm{Mi}^{\mathrm{i}}$ neralogy. However, Vauquelin obtained a precipitate by pouring chromate of potash into proto-sulphate of iron, which he has found to be composed of oxide of iron and oxide of chrome, and is analogous to the chromic ore of the Var, particularly when the latter is calcined. Other chromites may be obtained with the muriates of manganese and of tin with oxide of chrome. 
That with tin is green; with manganese chesnut-brown. They have all very similar properties : they dissolve in acids, and are precipitable from them without decomposition; the chlorate and nitrate of potash change them into alkaline chromates, and metallic oxides. I I have tried, but without success, several methods of separating them by analysis. With chlorate of potash they undergo a combustion similar to that of nitre and cream of tartar. A soluble chromate is indeed obtained, but the oxides of iron, of manganese, or of tin, retain much of the chromic oxide. Muriate of chrome renders muriate of manganese very soluble in alcohol; caustic alkalies cannot separate the whole of the oxide of tin from the oxide of chrome. These compounds deserve a fuller examination.

\section{Chromaie of Lead.}

It is well known that a reddish chromate of lead is obtained by precipitating acetite of lead with an alkaline chromate of potash ; but if the sub-acetite of lead and neutral chromate are used, both boiling hot, a yellow precipitate falls down, which in a few moments passes into a most brilliant orange-red. This tint may be heightened by boiling a little alkali with the red, or even with the yellow chromate of lead. I have nade a comparative analysis of the yellow and the red artificial chromate, and the native red lead of [Siberia. All of them give exactly the same proportion between the acid and the oxide. They are neutral chromates, only the red chromate contains a small quantity of alkali, apparently from 1 to $1 \frac{1}{2}$ per cent. The method which I used in these analyses was to dissolve the chromate in muriatic acid, which in a boiling heat became muriate of chrome; then to precipitate the lead by sulphuretted hydrogen, the oxide of chrome by ammonia; and lastly, to evaporate to obtain the muriate of potash. All the alkalies will change the fine yellow of the chromate of lead, and also of bismuth, into red.

It remains to inquire whether the alkali is combined with the chromic acid, the oxide of lead, or the chromate of lead. For this purpose, I treated a very pure chromate of lear and bismuth in excess with a small quantity of alkali, assisting the action by heat. After some instants the liquid had ceased to redden turmeric, and had assumed a yellow tint. Sometimes the turmeric test showed the absence of free alkali before the liquid changed colour, at which time the chromate contained free oxide of lead. Indeed, if a little litharge is added to the chromate along with the alkali, it will become red without losing chromic acid. One may even obtain red chromate by boiling together chromate of potash and litharge.

It follows from these facts that the alkali appears to be comVol. 59. No. 286. Feb. 1822. R bined 
bined with the oxide of lead; and that this compound, united to chromate of lead, gives rise to the red chromate, which thus contains a little more oxide of lead than the neutral chromate. A few drops of dilute nitric acid take away from it immediately its red colour, by dissolving the alkali with a little of the oxide of lead. I examined whether the red lead of Siberia, which is also yellow when reduced to powder, might contain a portion of alkali ; I found in it, after taking every precaution, a little lime, but J am ignorant whether or not it is accidental.

XXXVI. Description of the Methods employed in determining the Altitudes of several of the principal Mountains and other remarkable Oljects visible from the Trigonometrical Station on Rumbles Moor, Yorkshire, By A Correspondent.

$$
\text { To Dr. Tilloch. }
$$

$\mathbf{P}$ REParatory to taking the field in the spring of last year, to collect the requisite data for determining the abovementioned altitudes, I deemed it advisable, so slender was my stock of information on the subject of terrestrial refraction, to make, during the winter, daily observations of the apparent altitude of a mountain, of which the elevation as well as that of the place of observation could be readily determined by levelling. Rumbles Moor and an observatory 67,082 feet distant, both situated within three miles of a canal communicating with the Irish sea, were ultimately mare choice of.

The instruments made use of in measuring the angles, were two horizon sectors, of which the following is a brief description :

The one first used consists of a 30 -inch achromatic telescope $a$ (see Plate II.) fixed in the hollow square frame of mahogany, $b$; to one of its vertical sides is attached a plate of brass, $c$, containing 10 degrees of elevation and an equal quantity of depression. The radius of the are is nearly 18 inches, admitting the divisions to be read off to $5^{\prime \prime}$ by the moveable index $d$, which carries with it the adjustable spirit-level $e$. When the line of vision is known to be parallel to the plane of the horizon (the index being at zero) the bubble of the level is adjusted to remain in the middle. The small cross level $f$ determines the vertical position of the divided plate, and the line of collimation is rendered parallel to it by means of a proof telescope. When the object is elevated or depressed, the corresponding angle is measured by the index $d$, properly levelled; that is, moved by the pinion $(h)$ until the displaced bubble is again in the middle. Granting the interior sides of the glass level parallel to each other, 